\title{
Sustainability Analysis Off-grid Community Solar PV Projects in Malawi
}

\author{
P.M. Dauenhauer, D.F. Frame \\ Department of Electronic and Electrical Engineering \\ University of Strathclyde \\ Glasgow, Scotland \\ \{peter.dauenhauer, damien.frame\} @strath.ac.uk
}

\begin{abstract}
The sustainability challenges of off-grid community energy projects using solar photovoltaics in Malawi have been widely acknowledged. However, little evidence has been produced regarding the factors that affect the sustainability of these projects. This paper presents the results of a nationwide study of community solar PV project sustainability in Malawi. The concept of sustainability as a holistic measure is defined and captured through field survey at 43 projects. A multi-factor scoring technique provides a relative ranking of the surveyed projects. The majority of projects have serious shortcomings undermining their ability to produce a positive impact as intended. The results provide useful insights to the design of solar PV projects for community energy practitioners and indicate that the underlying challenges are both internal and systematic, from a poor technical design approach to limitations in the skills required to effectively manage such projects.
\end{abstract}

Keywords - Solar PV, Community Energy, Energy Poverty, Sustainable Development, Off-Grid Renewable Energy.

\section{INTRODUCTION}

Globally, nearly 1.3 billion people lack access to electricity. The sub-Saharan African country of Malawi currently supplies only $9 \%$ of its population overall [1]. Compared to other African countries, Malawi's rural electrification ranks relatively low at only $5 \%$. Those with access currently experience blackouts on a regular basis. For public institutions such as primary schools, the situation is equally grim. UNESCO reported only $10 \%$ of primary schools and $52 \%$ of lower primary schools had access to electricity in 2012 [2].

For many developing countries, with minimal centralized grid coverage and dispersed populations, off-grid solutions such as stand-alone PV systems are the most promising nearterm option for basic services such as lighting and charging of mobile phones. Although they do not match the quality of supply (in some cases) of a grid-connection, they nevertheless provide important benefits and often to the poorest. The provision of basic electrical services to remote schools and health clinics is a prevalent application of solar PV.
Internationally, the investments planned under the Sustainable Energy for All (SE4ALL) framework foresee a substantial role for off-grid solutions in achieving universal energy access [3]. The World Bank has also identified a role for off-grid technologies and community involvement in rural electrification projects [4]. For these investments to realize the intended benefits, it is critical that the projects and technologies function as designed.

Local development can be accelerated with electricity access but implementation of projects remains a major challenge [5]. Benefits arising from electricity access include improved health and educational outcomes that raise the quality of life and opportunities for affected populations. Yet these benefits are only achieved if the underlying technological systems remain functional. Unlike adoption of mobile phones and pico-solar-products such as solar lanterns, communitylevel solar PV systems cannot simply be installed, forgotten, and expected to function over a potential lifetime, defined by its technological expectations, of 20-plus years.

Sustainability of such projects is not a trivial matter. Research in this area has developed and implemented general frameworks for understanding the sustainable development aspects of rural electrification programs. These include the technical, economic, social, institutional, and environmental pillars of sustainability [6]-[8]. In these frameworks, many of the assumptions underlying the framing of sustainability are intuitive. Outside of technology choice and engineering design, factors cover many other domains deemed critical for the project survival. A project will 'fail', no matter the level of design robustness, if it lacks sufficient local acceptance, capacity to manage operations, or sufficient financial means to maintain and replace equipment when needed. Although frameworks of this type allow projects to be scored and ranked against each other in terms of sustainability, the scoring is relative to the project set rather than an absolute score indicating the true sustainability prospects. Furthermore, there is no generally accepted and systematic approach for detailed analysis of absolute sustainability. This limits the extent to which learning has been possible for key questions such as the relative importance of the different factors and the minimum 
sustainability requirements per factor for different deployment models.

Sustainability of off-grid community energy projects in Malawi has been a research target within the Malawi Renewable Energy Acceleration Programme (MREAP), a coordinated multi-objective development program funded by the Scottish Government. A 2012 evaluation provided a qualitative basis for understanding the sustainability issues experienced. Technical design weakness, lack of local technical capacity and ownership issues were identified [9]. In 2015, a Solar PV sustainability study was commissioned by MREAP to provide quantitative evidence in the sustainability challenges facing the existing stock of community energy projects in the country [10]. This was designed to complement the earlier evaluation and define a multi-dimensional framework that could be used in sustainability analysis.

This paper presents the results of the survey implemented in the study. These have direct relevance for project implementers in Malawi, particularly at the institutional level. The sustainability issues discussed pervade all energy access projects, hence the results and discussion presented here also have international relevance. In addition to the main contribution of detailed insights on the sustainability of systems currently deployed in Malawi, the proposed methodology for sustainability analysis provides a first step towards a framework for systematic analysis of sustainability against recognized baselines. This type of analysis is necessary to explore the interaction between, and relative importance of, the sustainability factors with respect to project 'success'.

The remainder of the paper is organized as follows: Section II describes the survey scope. Section III defines sustainability and discusses the study methodology. Sections IV-VIII recount the results related to each sustainability theme. Section IV presents a method for ranking the surveyed projects as well as discusses the results. Section $X$ includes a generalized discussion on the results as it pertains to sustainability of solar PV projects in Malawi. Concluding remarks are in Section XI.

\section{SURVEY SCOPE}

TABLE I details the 43 projects surveyed within the three main regions: North, Central, and South. The dominance of Primary schools and Health Centers, is deemed to be representative of the national picture of off-grid PV installations. The three 'Other' projects were two Teacher Development Centers and a Youth Club. The term 'project' refers to the site location where a PV installation has taken place, e.g. at a primary school. In most cases there are numerous individual PV systems within a project that provide a range of services to the stakeholders. The majority of systems are installed on a per building basis. In addition, each system may provide a range of services to a number of rooms within that building. The questionnaire was therefore designed to capture data at project level, system level and room level.

\section{SUSTAINABILITY ANALYSIS}

A robust analysis of sustainability requires an appropriate framework that includes a definition of sustainability, measureable indicators and a method for scoring and ranking the overall sustainability of a project.

TABLE I. SYSTEMS SURVEYED By TYPE AND REGION

\begin{tabular}{|l|l|l|l|}
\hline \multicolumn{1}{|c|}{ Type } & Central & North & South \\
\hline Primary Schools & 8 & 6 & 3 \\
\hline Secondary Schools & 2 & 2 & 1 \\
\hline Health Centers & 6 & 5 & 7 \\
\hline Other & 0 & 0 & 3 \\
\hline
\end{tabular}

\section{A. Definition of Sustainability}

Due to its ubiquitous use, it is necessary to adopt a working definition of "sustainability". Unlike other definitions which are targeted towards the global goal of sustainable development and are laregely irrelevant at the project level [6], or are outcome focused [11], the working definition used here is: "The systematic preparedness for a project to maintain an electricity service provision over its life span". Key factors of sustainability have been derived from two main sources: indicator frameworks for evaluating sustainability [6]-[8], and off-grid, solar PV project design guides and toolkits [12]-[17]. The factors identified are: technical, economic, social, organizational, and environmental. In the context of this study environmental sustainability was not considered.

\section{B. Sustainability Indicators}

In order to survey and assess the sustainability of PV systems, a set of indicators were developed based on those identified in the literature and what was understood to be feasibly available from a questionnaire based survey.

\section{1) Technical}

Technical sustainability relies on an appropriate system design and components that perform to an expected degree of reliability. The core components of off-grid systems are: solar panels, batteries and power electronic devices such as inverters and charge controllers. Selecting and sizing these components correctly with respect to anticipated electrical demand patterns is critical to the sustainability of the system. The key factors for assessing technical sustainability were identified as the type and state of components deployed, and the sizing of the key components (batteries and PV panels) with respect to the expected usage.

\section{2) Economic}

Economic sustainability concerns the continued financial well-being of the off-grid project. The key factors for assessing economic sustainability were identified as the presence of financial management structures or process and a qualitative estimate of typical monthly income, operation and 
maintenance costs. Due to the limitations in data, the project cash flow, positive or negative, was used as a proxy for financial health of a project.

\section{3) Social}

The key social sustainability factors for the PV systems surveyed in this work were identified as the level of community involvement and contribution with the inception and ongoing management of the project. Incidence of theft was adopted as a general measure of the wider community sense of ownership.

\section{4) Organizational}

The organizational sustainability is primarily concerned with the capacity of the organization (or individuals) to manage the project and underlying electrical system. The presence of technical, management and financial skills along with appropriate training strategies were hence adopted as the key factors indicating organizational sustainability.

\section{5) Symptoms of poor sustainability}

Based on the working definition of sustainability, a reduction in the provision of electricity service below that expected by the users is a symptom of poor sustainability. Therefore the survey aimed to capture information on the general working state of each system, the expected electricity service, and the actual electricity service delivered. These observed measures should be understood as a resulting state rather than grouped as a technical sustainability measure. Such a resulting state can clearly be influenced by a number of nontechnical factors for example lack of financial resources or competent system management. This differs from previous work where the inability of a system to deliver the expected electricity service was itself considered an indicator of technical sustainability [6]-[8].

TABLE II. SUMMARY OF TECHNICAL SUSTAINABILITY RESUlTS

\begin{tabular}{|l|l|l|}
\hline \multirow{4}{*}{ Indicator } & \multicolumn{1}{|c|}{ Parameters } & \multicolumn{1}{c|}{ Value } \\
\hline \multirow{4}{*}{$\begin{array}{l}\text { Basic } \\
\text { Installation } \\
\text { Measures }\end{array}$} & North Facing Systems & $94 \%$ \\
\cline { 2 - 3 } & Roof Mounted & $98 \%$ \\
\cline { 2 - 3 } & Solid enclosure present for battery & $83 \%$ \\
\cline { 2 - 3 } & Ventilated batteries & $30 \%$ \\
\cline { 2 - 3 } & System showing signs of tampering & $32 \%$ \\
\hline \multirow{4}{*}{$\begin{array}{l}\text { Component } \\
\text { Details }\end{array}$} & Alt. (low quality) branded Solar Panels & $25 \%$ \\
\cline { 2 - 3 } & Alt. (low quality) branded batteries & $23 \%$ \\
\cline { 2 - 3 } & DC only systems & $47 \%$ \\
\cline { 2 - 3 } & Poor health indicator shown on battery & $43 \%$ \\
\cline { 2 - 3 } & Light fitting included working bulbs & $70 \%$ \\
\cline { 2 - 3 } & Lighting technology mode & $\mathrm{CFL}$ \\
\cline { 2 - 3 } & CFL bulb rating mode & $11 \mathrm{~W}$ \\
\hline \multirow{4}{*}{$\begin{array}{l}\text { System } \\
\text { Design }\end{array}$} & Systems with undersized PV array & $44 \%$ \\
\cline { 2 - 3 } & Systems with undersized battery bank & $83 \%$ \\
\hline
\end{tabular}

\section{Scoring and Ranking Sustainability}

With a set of indicators established, and data gathered against these indicators for a set of projects, it is possible to assign a score for each project, per indicator, and then rank the projects in terms of relative sustainability as per the literature [7]. There is noticeable gap in the literature on techniques for ranking as well as the exact usages; any attempts have to been received as theoretical until they can be robustly validated. The relative rankings are not necessarily an accurate predictor of absolute sustainability (a project ranking highly against its peers may still be inherently flawed); however, the process of scoring and ranking developed in this work allows for comparative analysis. This process facilitates discussion of the relative importance of each sustainability factor within varying project implementation models. The scoring and ranking approach taken and results are described in Section VIII.

\section{TEChNiCAL SUSTAINABILITY RESUlTS}

The survey results for technical sustainability are summarized in TABLE II.

\section{A. Basic Installation Measures}

Correctly positioning and orientating PV panels along with appropriate battery enclosures are basic requirements of a PV installation. Although most systems appear to meet the basic requirements of panel installation, many have insufficient battery enclosures and have experienced tampering.

\section{B. Component Details}

The results indicate that well-known, quality brands are the most prevalent PV system components; however, high numbers of 'alternative' brands are also evident. $23 \%$ of battery brands and $25 \%$ of PV panel brands observed have been categorized as 'other'. Inverter brands appear to be a range of imported brands with unknown reputation and quality. Component ratings indicate approximately half of systems are single panel, single battery systems, implying a high penetration of staff home systems around school and health center installations. There is relatively low incidence of missing components, indicating that theft rates are low. The component most likely to be missing is an inverter which, as an easily removable component that can be utilized flexibly outside of the system, is an unsurprising result. Inverters are not ubiquitous across the systems, $47 \%$ of systems are DC only - implying a focus on lighting as the priority service. Battery health appears to be a major issue with $43 \%$ of the observed battery banks displaying a poor health indicator. The lighting systems primarily utilize energy saver CFL bulbs, however only $70 \%$ of light fittings contain a working bulb.

\section{Analysis of System Design}

The survey data provides the expected usage (or electrical load) of the system as well as the installed components that are attempting to meet that load. By applying established PV 
system design methods [18], an estimate of the required system sizing can be obtained from the expected usage data. Fig. 1 displays the estimated fitness for purpose of the PV array size and battery banks for each system as the ratio of installed capacity to estimated required capacity as indicated by the solid horizontal line. In both cases there are systems that appear to have dramatically oversized or undersized capacity.

It is acknowledged that the data for this estimation is based on a respondent response and subject to the likelihood of error in the provided data. Nevertheless, the majority of results appear sensible and it is a significant finding that $44 \%$ of systems have undersized PV arrays and $83 \%$ of systems have undersized battery banks.

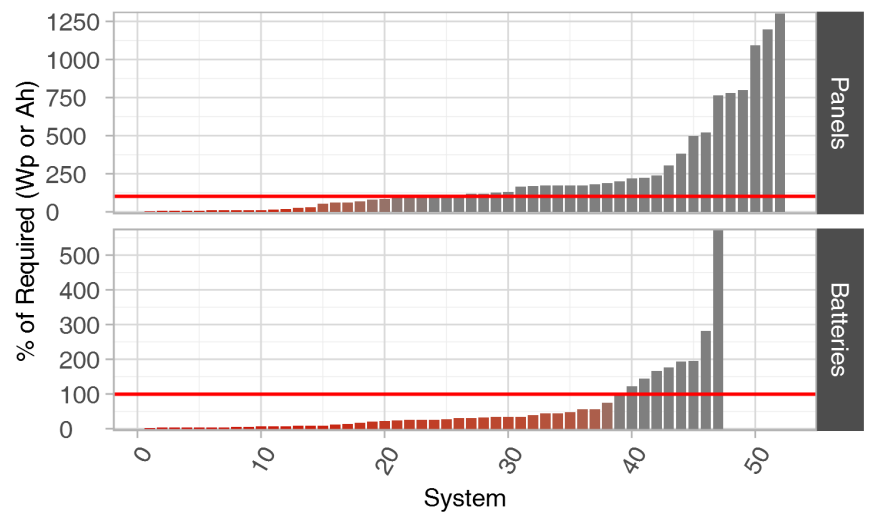

Fig. 1. PV and Battery Estimated Fitness for Purpose

\section{ECONOMIC SUSTAINABILITY RESULTS}

The survey asked, at a project level, for an estimate of typical monthly income and expenditure. TABLE III. reports the headline economic sustainability indicators. 22 of the projects surveyed did not have any economic data for analysis which was interpreted as not having an economic system at all. Only 11 projects $(27 \%)$ reported an income of any size. Of these only 6 (15\% of all projects) are included in the $22 \%$ of projects that also have a bank account.

For the full 40 projects, the mean and median monthly income was 1,832 MW, and 0 MWK respectively. Mobile phone charging dominates income generation sources and expenditure on equipment is primarily on light bulbs and inverter replacement. Within the small group of projects that are managing to generate income and had a bank account, there are some case studies available that indicate a community managed financial model could achieve a degree of economic sustainability in terms of meeting running costs if the systems were technically robust and did not experience an unduly high degree of fault. However, even for the best performing system in the data set it is impossible to expect that it could save enough of its income to replace the likely capital expenses as the system ages. No projects were able to identify savings targets that would be required to support the maintenance or replacement of system assets or current progress against these targets. Several projects reported expenses but could not explain their income sources. Only a token few projects could produce log books or accounting for sales of any goods/services associated with their energy projects and these had large gaps in available data.

TABLE III. SUMMARY OF ECONOMIC SUSTAINABILITY RESUlTS

\begin{tabular}{|l|l|l|}
\hline Indicator & \multicolumn{1}{|c|}{ Parameters } & \multicolumn{1}{|c|}{ Value } \\
\hline \multirow{4}{*}{ Income } & Projects with any monthly income & $27 \%$ \\
\cline { 2 - 3 } & Mean monthly income & $1832 \mathrm{MWK}$ \\
\cline { 2 - 3 } & Median monthly income & $0 \mathrm{MWK}$ \\
\cline { 2 - 3 } & Maximum Monthly income (all projects) & 20,000 \\
& & $\mathrm{MWK}$ \\
\cline { 2 - 3 } Sources & Projects with a bank account & $22 \%$ \\
\hline \multirow{5}{*}{ Types of } & TV / video shows & $22 \%$ \\
Expenses & Room Rental & $3 \%$ \\
& Mobile phone charging & $75 \%$ \\
& Light Bulbs & $36 \%$ \\
& Inverter replacement & $29 \%$ \\
& Batteries & $20 \%$ \\
\hline
\end{tabular}

\section{SOCIAL SUSTAINABILITY RESUltS}

The social sustainability results, summarized in Table IV, indicate a relatively limited involvement by social actors in many cases. There is significant lack of ownership over projects. Nearly half of projects identified no stakeholders involved in the ongoing management.

Community consultation at project inception was around $60 \%$ and equally for whether a needs assessment was completed. As a gauge of community ownership or buy-in at inception, very few projects have any record of community contribution. This suggests that even when the community is consulted, the community has only token involvement. Furthermore, community engagement is not sustained after inception; only $20 \%$ project stakeholders meet on a regular basis (at least monthly). Any oversight or management by district governance (such as by Health or Education offices) occurred in only $22 \%$ of projects. When it occurs, district involvement is inconsistent; it was not connected to the level of functionality of the system.

TABLE IV. SUMmary OF SOCIAL SUSTAINABILITy RESUlts

\begin{tabular}{|l|l|l|}
\hline \multicolumn{1}{|c|}{ Indicator } & \multicolumn{1}{|c|}{ Parameters } & \multicolumn{1}{c|}{ Value } \\
\hline \multirow{2}{*}{ Inception } & Community consulted prior to installation & $62.5 \%$ \\
\cline { 2 - 3 } Activities & Needs Assessment Completed & $60 \%$ \\
\hline \multirow{2}{*}{ Community } & Labor & $10 \%$ \\
& Materials & $7.5 \%$ \\
& Monetary & $2.5 \%$ \\
\hline \multirow{5}{*}{ Stakeholders } & \multicolumn{1}{|c|}{ Nominal Decision Makers } \\
& Community Committee/Gathering & $55 \%$ \\
& Local Individual & $17.5 \%$ \\
& External Stakeholder & $7.5 \%$ \\
& No stakeholders identified & $20 \%$ \\
\hline
\end{tabular}




\begin{tabular}{|c|c|c|}
\hline Indicator & Parameters & Value \\
\hline & \begin{tabular}{l}
$\quad$ Stakeholders Involved in Ongoing \\
\multicolumn{1}{c}{$\quad$ Management } \\
Traditional authority \\
NGO \\
Government (not district) \\
District government \\
Community Based Organization \\
School Committee \\
Student Representatives \\
School Representatives \\
None
\end{tabular} & $\begin{array}{l}2 \% \\
7 \% \\
6 \% \\
7 \% \\
9 \% \\
7 \% \\
4 \% \\
4 \% \\
47 \%\end{array}$ \\
\hline & District involvement (in any way) & $22.5 \%$ \\
\hline & $\begin{array}{l}\text { Frequency of Meetings } \\
\text { Never } \\
\text { Every } 2 \text { Months } \\
<1 \text { per month } \\
\text { Monthly } \\
\text { Weekly }\end{array}$ & $\begin{array}{l}70 \% \\
12.5 \% \\
2.5 \% \\
12.5 \% \\
2.5 \% \\
\end{array}$ \\
\hline \multirow{4}{*}{$\begin{array}{l}\text { Theft and } \\
\text { breakdown }\end{array}$} & System failure experienced at least once & $80 \%$ \\
\hline & Failure was resolved & $72.5 \%$ \\
\hline & Theft experienced by project & $27.5 \%$ \\
\hline & Theft was satisfactorily resolved & $17.5 \%$ \\
\hline
\end{tabular}

Finally, though theft was present it can be considered relatively low, occurring in $27.5 \%$ of projects. However, of the projects which experienced theft only $17.5 \%$ were considered resolved adequately. An open question is the adequacy of rule of law to protect the solar PV project. Introduction of the relatively expensive equipment provides an incentive for theft. It is apparent that alternative means of security such as cages and existence of a security guard are required.

\section{ORGANISATIONAL SUSTAINABILITY RESULTS}

TABLE V. SUMMARY OF ORGANIZATIONAL SUSTAINABILITY RESUlTS

\begin{tabular}{|c|c|c|}
\hline Indicator & Parameters & Value \\
\hline \multirow{3}{*}{ Training } & Projects with training delivered prior to installation & $50 \%$ \\
\hline & $\begin{array}{l}\text { Type of Training delivered } \\
\text { Technical } \\
\text { Financial } \\
\text { Management }\end{array}$ & $\begin{array}{l}12.5 \% \\
5 \% \\
20 \%\end{array}$ \\
\hline & Projects with Ongoing training (in the last year) & $20 \%$ \\
\hline $\begin{array}{l}\text { Roles } \\
\text { present }\end{array}$ & $\begin{array}{l}\quad \text { Roles Present at Project (currently) } \\
\text { Technical } \\
\text { Financial } \\
\text { Management }\end{array}$ & $\begin{array}{l}50 \% \\
15 \% \\
67.5 \%\end{array}$ \\
\hline \multirow[t]{2}{*}{$\begin{array}{l}\text { Supply } \\
\text { Chain }\end{array}$} & $\begin{array}{l}\quad \text { Project Access to Spare Light Bulbs } \\
0-5 \mathrm{~km} \\
5-20 \mathrm{~km} \\
20+\mathrm{km} \\
\text { unknown }\end{array}$ & $\begin{array}{l}0 \% \\
12.5 \% \\
67.5 \% \\
12.5 \%\end{array}$ \\
\hline & Maintenance agreement is in place & $52 \%$ \\
\hline
\end{tabular}

TABLE $\mathrm{V}$ shows that training at install was received by only half of the projects and very few have any ongoing training. Financial skills and training are particularly limited. Since the skill levels were self-reported and measure of level not specified, they may be over-reported. Nearly half of all projects have no ongoing maintenance arrangements in place. This would incorporate both internal and/or external maintenance provision such as through a PV contractor. The simplest maintenance requirement for a PV system is to replace light bulbs. $12.5 \%$ of systems have no knowledge of where to obtain bulbs. $67.5 \%$ of projects are over $20 \mathrm{~km}$ from the nearest known supply of bulbs.

\section{SUSTAINABILITY SYMPTOM RESUlTS}

\section{A. General System Performance}

The symptoms of poor sustainability are described below and the results are summarized in TABLE VI.

TABLE VI. SUMMARY OF SUSTAINABILITY SYMPTOMS

\begin{tabular}{|l|c|l|c|}
\hline Symptoms & \% Systems & Symptoms & \% Systems \\
\hline All service lost & $38 \%$ & All power lost & $4 \%$ \\
\hline All lights lost & $7 \%$ & Power in day only & $5 \%$ \\
\hline Lights in day only & $7 \%$ & $\begin{array}{l}\text { Power for short } \\
\text { time at night }\end{array}$ & $5 \%$ \\
\hline $\begin{array}{l}\text { lights for short } \\
\text { time at night }\end{array}$ & $12 \%$ & $\begin{array}{l}\text { \% Systems with any } \\
\text { Symptom }\end{array}$ & $45 \%$ \\
\hline
\end{tabular}

The symptoms are designed to capture whether the system is either working, in a total state of failure, or in a partial state of failure, i.e. some services work but only during sunlight hours. $45 \%$ of systems have experienced some kind of symptom with their lighting or power service, however most significantly, $38 \%$ of systems have lost all service.

\section{B. Performance of Lighting Systems}

Lighting system performance is summarized in Table VII. Comparison of the numbers of bulbs working versus installed fittings on a per room basis indicates that rooms will mainly have either all bulbs working ( $48 \%$ of rooms) or no bulbs working ( $45 \%$ of rooms).

TABLE VII. LIGHTING System PERForamnCE

\begin{tabular}{|l|l|l|}
\hline $\begin{array}{l}\text { Lighting } \\
\text { System } \\
\text { Performance }\end{array}$ & Rooms with all lights functional & $48 \%$ \\
\cline { 2 - 3 } & Rooms with no lights functional & $45 \%$ \\
\hline $\begin{array}{l}\text { Functional } \\
\text { Perofrmance }\end{array}$ & hours of lighting (actual)/week & Mean $=13.57$ \\
\cline { 2 - 3 } & hours of lighting (expected)/week & Mean $=23.45$ \\
\hline
\end{tabular}

This can partially be attributed to associated staff household installations with small numbers of light fittings where an all or none situation may be likely. In addition, it was observed by the project team that where light failures start to occur within a project, working bulbs will be repositioned in 
priority rooms to provide a good quality service in at least one room as opposed to partial service in multiple rooms.

As a measure of system functionality, the expected weekly usage is compared with the recorded actual usage on a room by room basis. The results show that performance is mainly polarized as either entirely meeting expectations or completely failing to meet expectations. Fig. 2 displays data for the expected weekly hours of lighting. These values are derived by multiplying expected days per week by expected hours per day for each room. The same process is conducted for actual hours of lighting delivered by the system. The resulting distributions indicate a significant gap between expected (mean 23.45 hours) and actual (mean 13.75).

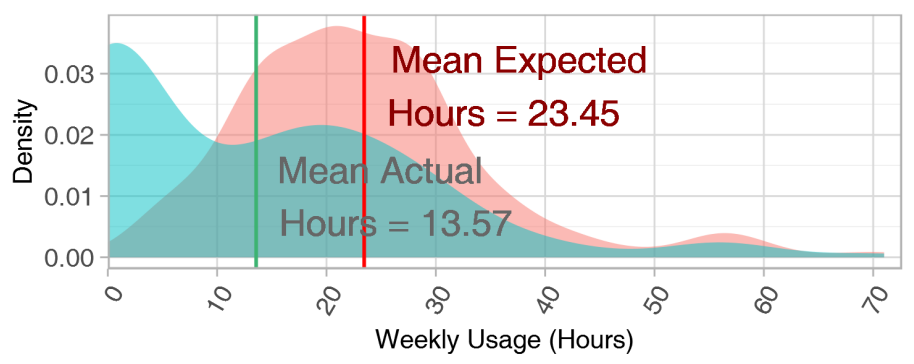

Fig. 2. Distribution of Weekly Lighting Hours (Expected and Actual)

\section{RANKING RESULTS}

In order to consider the question of overall sustainability, a ranking process has been applied to the surveyed systems. For each of the sustainability factors a subset of the indicators described above are used for ranking. Each indicator has been normalized to a range between 0 and 1 (or binary 0 and 1 for yes/no questions), and then combined with equal weighting to form a total score for each factor. All factors are also then combined with equal weighting to form an aggregate sustainability score between 0 and 1 .

Component quality, battery health, and the fitness for purpose of both PV array and battery bank design have been used as the ranking metrics for technical sustainability. The normalized absolute value of net income and yes/no bank account existence represent economic sustainability. The social sustainability ranking includes yes/no scores for: existence of a needs assessment, existence of community contributions, whether the district governance is involved in the project, whether there are any stakeholders or not, and incidence of theft. Management meetings were simplified to score 1 if they were reported to occur at all, and 0 if not. The indicators relating to the presence of technical, financial, management skills and training, plus the presence of a maintenance arrangement have been used as binary scores for organizational sustainability.

The scoring and ranking of the sustainability factors was compared to symptoms of sustainability in order to provide some insight on any link between relative sustainability ranking and the current level of system performance. The two metrics used for this comparison are the system performance ratio (expected vs actual) and the system status (working, partial failure or total failure), as described in Section VIII. It should be noted that both performance ratio, and even more so the status metric, represent a relatively short-term perspective of the functionality of the system.

A simple linear regression was undertaken to determine the correlation between scoring approach and performance ratio (actual vs. expected usage). The results are summarized in Table VIII below. No significant correlation was observed for any of the sustainability scores.

TABLE VIII. CORRELATION BETWEEN SUSTAINABILITY SCORES AND PERFOMANCE RATIO

\begin{tabular}{|l|l|l|l|l|}
\hline Model & \multicolumn{1}{|c|}{ Coef } & \multicolumn{1}{c|}{$\boldsymbol{P}$} & $\boldsymbol{P r}(>|\boldsymbol{t}|)$ & \multicolumn{1}{c|}{$\boldsymbol{R}^{\mathbf{2}}$} \\
\hline Total Score Perf.Ratio & 0.1608 & 0.336 & 0.738 & 0.0018 \\
\hline Tech Score Perf.Ratio & 0.1517 & 0.735 & 0.465 & 0.0088 \\
\hline Econ Score Perf.Ratio & 0.5213 & 2.003 & 0.0549 & 0.1253 \\
\hline Soc Score Perf.Ratio & 0.0967 & 0.319 & 0.7506 & 0.0016 \\
\hline Org Score Perf.Ratio & -0.243 & -0.879 & 0.383 & 0.0119 \\
\hline \multicolumn{5}{|c|}{ Significance: $* * *=0.001, * *=0.01, *=0.05$} \\
\hline
\end{tabular}

In Fig. 3 the aggregate ranking is shown for each system along with the ranking for each factor. The systems are ordered based on the aggregate ranking. In addition, the observed status of each system is also provided. System rankings are color coded on a gradient of white (low score) to dark green (high score) based on their score in the range 0-1. Hashed lines represent unavailable results for economic sustainability. System status is represented as 0 (total failure), 0.5 (partial failure) and 1 (working) as derived from the observed symptoms.

Intuitively it could be expected that a higher aggregate sustainability score should correspond to a greater likelihood of good system performance. However, this is not clearly apparent for this set of results. From a visual analysis it seems that there is some indication of such a relationship, with systems ranked least sustainable generally experiencing failure and those ranked most sustainable generally observed to be working well. However, there are many anomalies with several systems ranked highly for sustainability also currently in a state of failure and vice versa. If the systems are reordered based on technical sustainability ranking a slightly closer relationship between ranked sustainability and performance is observed. Re-ordering in a similar way with any of the other symptoms does not have a similar effect. The lack of a strong relationship between the sustainability rankings and the observed system performance is a reflection of the relative nature of the ranking and the sustainability indicators used in this study. The indicators are binary in many cases and can only provide an 'indication' of sustainability rather than a detailed and accurate gauge of absolute sustainability that can be correlated to actual system 
performance. These results clearly demonstrate that although sustainability analysis frameworks which employ basic indicators and a relative ranking can only provide a limited degree of insight into how well a system will actually perform.

\section{DiscussiON}

System performance is defined by the working state of the system and its ability to meet expectations. Performance overall has been identified as poor. There are no exemplar projects that allow a comparative analysis of factors linked to high performance. For the many systems in a state of failure, the multi-faceted nature of sustainability and the scope of this retrospective study makes identifying specific underlying reasons for that failure difficult in most cases. The technical analysis provides an initial indication that system design (battery bank sizing in particular) is a critical factor and can be linked to more robust and higher performing systems; however, for this data set, statistical support was not established for that premise. There is also evidence of systems that are technically weak maintaining a high level of performance through access to external finance that quickly returns systems to working order after failure.

An interesting aspect of the data is that the expected performance of the lighting systems are mainly described as either completely not meeting expectations or as fully meeting expectations. It is difficult to say if this is a wholly accurate representation of the system or an indication of difficulty in the questioning process to articulate and capture degrees of satisfaction. Nevertheless, large numbers of systems can be said to be not meeting expectations.

The standard components that comprise PV systems (PV panels, Batteries, Charge Controller and Inverter) are found to be prevalent in system design as expected. However, there are significant numbers of obscure brands and hence doubts over component quality. Light bulbs are primarily CFL and experience high failure rates.

Sizing and quality of PV system components is critical to appropriate design. Standards in this respect appear to be lacking. The results of this study indicate that design and installation is often below standard and the overall technical sustainability is poor. Although the Malawian renewable energy sector is regulated and there is an accreditation process of installers and suppliers, there may still be serious issues with the supply chain and design process. Specific suppliers and installers are not identified in the survey therefore poor technical sustainability cannot be linked to the use of nonaccredited suppliers.

The ultimate responsibility for ensuring appropriate technical standards for PV installations in Malawi lies with the Malawi Energy Regulatory Authority (MERA); however, with numerous local and international organizations working with

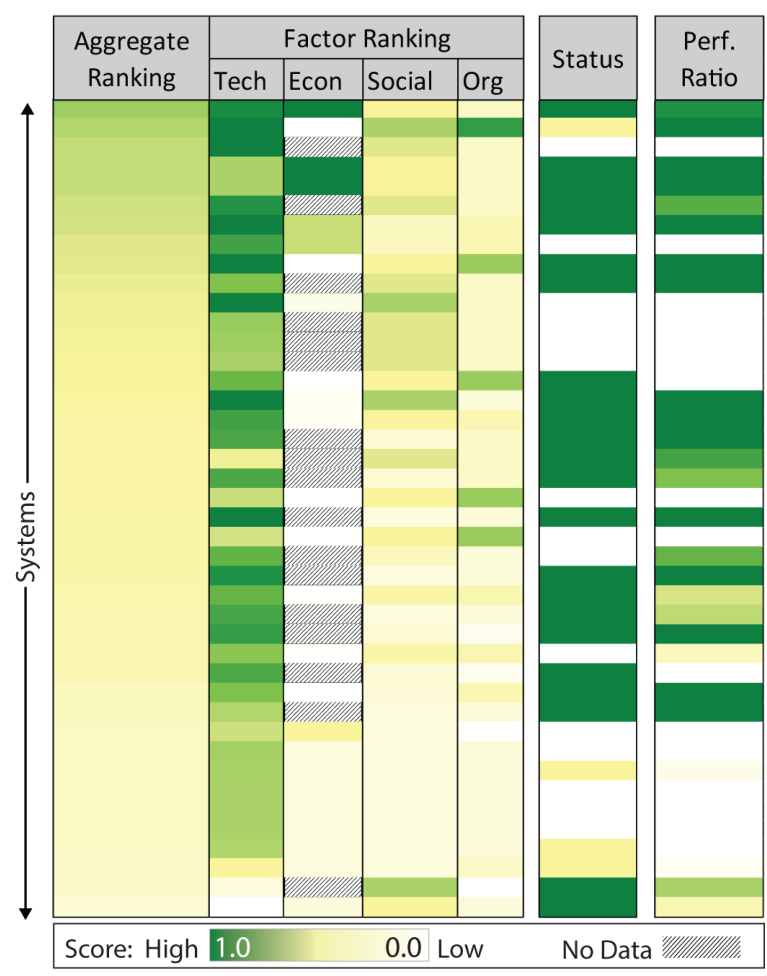

Fig. 3. Ranking of Systems by Sustainability Score. Ordered highest to lowest by Aggregate Ranking

communities across Malawi there is significant chance of proper process being bypassed.

It should therefore be the aim of the sector to ensure that all MERA accredited suppliers are using suitably robust design standards and components. Likewise efforts to better inform consumers (in this case purchasing agents for institutional level PV systems) on minimum quality requirements would allow for better choices during procurement.

This study highlights the need for additional research and consensus on the methods used for, and indeed basic understanding of the definition of, sustainability analysis. We have defined the most sustainable projects as those scoring highest within the sustainability rankings and justified the choice of indicators. However, the lack of correlation between the sustainability scores and an observation of the project's ability to meet usage expectations raises methodological questions, namely, is sustainability scoring relevant to absolute sustainability? Or, does meeting usage expectations at a specific moment in time properly represent sustainability?

It is essential that the systems are sufficiently technically reliable to maintain a level of performance that available financial resources can support. This implies that projects generate the funds necessary for life-cycle costs, and most critically, 3-5 year battery replacement. The encompassing sustainability issues of community engagement, social and 
organizational structures are also of importance, however in the surveyed systems, insufficient to guarantee sustainability on their own.

The existence of high scoring projects which simultaneously have below average status metrics or performance ratios does not have a simple explanation. In essence, the proposed ranking method defines a project as highly sustainable if it is appropriately designed, has relatively strong financial performance, is embedded and accepted within the community, and has the skills available to manage the project. This definition can be equated to preparedness rather than current condition and is one justification for the lack of correlation. Thus it is possible for a high scoring project to experience a dip in performance, but nonetheless be in a position to mitigate the underlying causes for the low performance. Equally, there are a number of surveyed systems that rank highly in many respects; however, their long term outlook is doubtful due to the lack of sufficient revenue and forthcoming requirement for battery replacement. Based on the survey responses, even a highly trained, organized and motivated community will be unlikely to maintain their system in the long term without a high standard of technical installation and a degree of external financial support for lifecycle costs. Therefore, it is not clear that an equal weighting across the factors is appropriate.

Lack of record keeping and subsequent limited use of evidence based decision making at the project level limited the data available to this study and appears to be commonplace for such projects. To correct this, a practical but standard set of relevant sustainability indicators could be implemented by project owners and operators for routine sustainability analysis and decision making. Work elsewhere [19] utilizing remote monitoring could likewise be implemented to gain time series data giving an accurate reflection of the technical and economic status of the project. Furthermore, there may be an absolute minimum requirement for each factor depending on the particular operational model, a nuance we have only brushed the surface of.

\section{CONCLUSIONS}

The sustainability picture is not encouraging across the surveyed set of projects. Elements such as detailed needs assessment, community engagement, establishment and training of management structures, good technical design, quality components, maintenance and operation structures, financial management and a business plan are lacking in many of the projects. Scoring sustainability factors and ranking projects relative to each other provides useful insights on the preparedness of projects. However, with regards to the absolute assessment of sustainability and accurate prediction of a system's ability to deliver an expected electricity service over time, there is clear value in further work to develop a more thorough understanding of the appropriate indicators and measurement methodologies required.

\section{ACKNOWLEDGMENT}

This work was supported by MREAP, funded by the Scottish Government from 2012-2015.

\section{REFERENCES}

[1] IEA (2014), "World energy outlook 2014," IEA, Paris

[2] UIS/ISU. UNESCO Institute for Statistic, n.d. Web. 29 May 2015.

[3] IEA (2011), "World energy outlook 2011," IEA, Paris.

[4] World Bank (2012), "Addressing the electricity access gap," Washington, DC: World Bank.

[5] Scott, A., Diecker, J., Harrison, K., Miller, C., Hogarth, J.R., Wheeldon, S., (2016) "Accelerating access to electricity in Africa with off-grid solar", ODI.

[6] Ilskog, E., "Indicators for assessment of rural electrification-An approach for the comparison of apples and pears," Energy Policy, Volume 36, Issue 7, July 2008, Pages 2665-2673, ISSN 0301-4215.

[7] Ilskog, E., Kjellström, B., "And then they lived sustainably ever after?-Assessment of rural electrification cases by means of indicators," Energy Policy, Volume 36, Issue 7, July 2008, Pages $2674-$ 2684, ISSN 0301-4215.

[8] Yadoo, A., "Delivery Models for Decentralised Rural Electrification: case studies in Nepal, Peru and Kenya," International Insitutte for Environment and Development, 2012, London.

[9] IOD PARC, "Evaluation of Off-grid Community Managed Renewable Energy Projects in Malawi" Malawi Renewable Energy Acceleration Programme, June 2012.

[10] University of Strathclyde, "MREAP Project Steering Group Meeting Minutes", Malawi Renewable Energy Acceleration Programme, 28 Nov 2013, Lilongwe, Malawi.

[11] Louie, H.; Dauenhauer, P.; Wilson, M.; Zomers, A.; Mutale, J., "Eternal Light: Ingredients for Sustainable Off-Grid Energy Development," Power and Energy Magazine, IEEE , vol.12, no.4, pp.70,78, July-Aug. 2014

[12] Corsair, H.J., "Causes of Success and Failure of Stand-alone Solar Electric Systems in Rural Guatamala," Ph.D. Thesis, Johns Hopkins University: United States, (2013).

[13] Terrado, E., Cabraal, A., Mukherjee, I., "Operational guidance for World Bank Group staff : designing sustainable off-grid rural electrification projects - principles and practices, "Washington, DC, World Bank, 2008.

[14] Finucane, J., Purcell, C., "Photovoltaics for community service facilities : guidance for sustainability," Energy Sector Management Assistance Program (ESMAP), Washington, DC, World Bank, 2010.

[15] United Nations Department of Economic and Social Affairs, "Indicators of sustainable development: guidelines and methodologies,' 2nd ed. New York, NY: UNDESA, 2001.

[16] International Atomic Energy Agency, "EEA. energy indicators for sustainable development: Guidelines and methodologies," 2005.

[17] I. Vera and L. Langlois, "Energy indicators for sustainable development," Energy, vol. 32, no. 6, pp. 875 - 882, 2007, third Dubrovnik Conference on Sustainable Development of Energy, Water and Environment Systems.

[18] Solar Energy International, "Photovoltaics: Design and Installation Manual", New Society Publishers, 2004.

[19] Best, S., "Energising local economies: Experiences of solar start-ups in Kenya's small-scale fishing and agriculture sectors," International Insitutte for Environment and Development, 2016, London. 